\title{
Genotipos de Staphylococcus aureus con fenotipo meticilino resistente, aislados de pacientes del H ospital Base de Valdivia
}

\author{
Myra Wilson $\mathrm{S}^{1 \mathrm{a}}$, Carola $\mathbf{0}$ tth $\mathrm{L}^{1 \mathrm{~b}}$, G ustavo Medina $\mathrm{S}^{\mathrm{lc}}$, \\ Laura 0 tth $R^{1 a}$, Heriberto Fernández J ${ }^{1 a}$, María Arce ${ }^{2 a}$, \\ Angela Zaror C2a, Víctor Lizama2a, Mónica Gil D4, \\ Ana María von Chrismar ${ }^{3 b}$. \\ Genotypes of Staphylococcus aureus \\ straing with methicillin resistant \\ phenotype
}

Background: Methicillin resistant strains of Staphylococcus aureus (MRSA) are an important cause of nosocomial infections. Aim: To determine the genotypes of MRSA strains. Material and methods: Fifty five strains of MRSA, isolated from patients hospitalized in Hospital Base Valdivia, were studied. The phenotype was determined through MicroScan ${ }^{\circledR}$ in all strains and by minimum inhibitory concentration (MC) in 41 . The genotype of the strains was analyzed by a duplex polymerase chain reaction (PCR) of the mecA gene, amplifying eight hypervariable AND regions associated to such gene. Results: According to MC, $88 \%$ of strains had a pattern of resistance against multiple antimicrobial (penicillin, ampicillin, cephradine, gentamycin, ciprofloxacin, lincomycin and erythromycin). Vancomicin resistan strains were not detected. Only 53 strains (96\%) had at least one of the eight hypervariable regions and were classified as MRSA. Genotypic patterns types 15 were the most commonly detected in $38 \%$ and $34 \%$ of strains, respectively. MicroScan ${ }^{\circledR}$ erroneously classified five strains in an incorrect phenotype, according to results obtained with duplex PCR MC results did not differ from those of duplex PCR. Conclusions: Duplex- PCR is a useful tool to detect hyper variable regions associated to mecA gene (Rev Méd Chile 2007; 135: 596-601).

(Key words: Drug resistance, bacterial; Methicillin; Staphylococcu aureus)

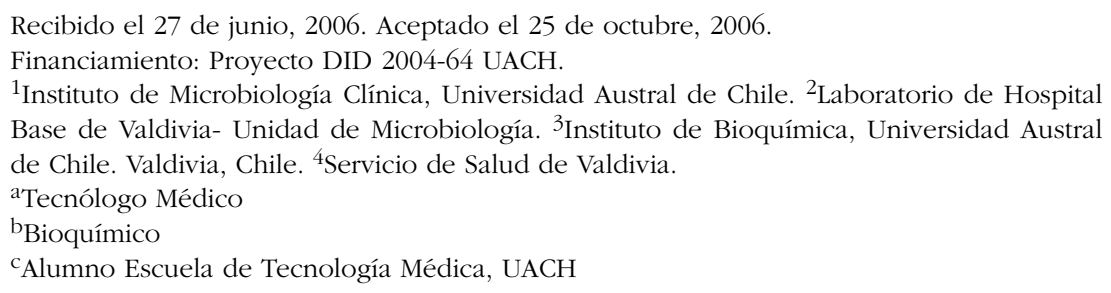


$S^{a}$ phylococcus aureus constituye un importante agente etiológico de diversas patologías infecciosas, entre las que destacan infecciones de piel y tejidos blandos, abscesos y septicemia ${ }^{1}$.

En 1961, Jevons ${ }^{2}$ describió por primera vez, en Londres, la aparición de cepas de Staphylococcus aureus resistentes a meticilina (SAMR), las que se han constituido en uno de los principales agentes de infección nosocomial a nivel mundial ${ }^{3}$.

En Chile, Lederman et $\mathrm{al}^{4}$ informaron por primera vez estas cepas en 1967. Desde entonces diversos autores han determinado una alta incidencia de infecciones por SAMR, especialmente nosocomiales, lo que implica un aumento en la morbilidad y mortalidad a nivel hospitalario ${ }^{5,6}$.

El mecanismo de resistencia a meticilina más importante lo constituye la síntesis de una nueva proteína fijadora de penicilina o penicillin binding protein (PBP), denominada PBP2a, la cual es capaz de mantener la integridad de la pared celular durante el crecimiento y la división celular cuando las PBPs habituales son inhibidas por los antibióticos ß-lactámi$\cos ^{6}$. Esta resistencia se debe a la incorporación en el $\mathrm{ADN}$ bacteriano de un elemento extracromosomal que contiene el gen mecA, encargado de codificar dichas proteínas. La expresión fenotípica de esta resistencia suele ser heterogénea, lo que significa que, a pesar que todas las células de una población poseen el gen, sólo algunas lo manifiestan, haciendo difícil su detección en el laboratorio por los métodos habituales ${ }^{5}$.

Se han detectado regiones "hipervariables" asociadas al gen mecA. Esta variabilidad ha sido utilizada con la finalidad de llevar a cabo estudios de epidemiología molecular de SAMR ${ }^{7}$.

Nuestro objetivo es determinar el genotipo de cepas de SAMR aisladas de pacientes hospitalizados en el Hospital Base de Valdivia, con el fin de conocer los genotipos presentes en nuestro hospital y relacionarlos con sus patrones de resistencia antimicrobiana y los servicios de hospitalización desde donde fueron aisladas.

\section{MATERIAL y MÉTODO}

Fueron estudiadas 55 cepas de Staphylococcus aureus que presentaban fenotipo de resistencia a meticilina, aisladas de pacientes hospitalizados en el Hospital Base de Valdivia entre marzo de 2004 y diciembre de 2005.
El fenotipo de resistencia a meticilina se determinó mediante MicroScan ${ }^{\circledR}$ en la totalidad de las cepas, siguiendo las indicaciones del fabricante. Sólo 41 cepas fueron analizadas mediante la determinación de concentración inhibitoria mínima (CIM) frente a oxacilina, según normas del NCCLS ${ }^{8}$. Además, se estudió la CIM frente a penicilina, ampicilina, vancomicina, cefradina, gentamicina, ciprofloxacino, lincomicina y eritromicina.

Para la genotipificación se siguió el protocolo descrito por Huygens et $\mathrm{al}^{7}$. Con este fin, se implementó un multiplex PCR con 8 set de partidores destinados a amplificar regiones hipervariables asociadas al gen mecA. Estas regiones corresponden a HVR, pUB110, Ins117, pT181, p1258 (I), p1258 (II), mecR1, IS256. El producto de amplificación de estas regiones corresponde a $300 \mathrm{pb}, 331 \mathrm{pb}, 215 \mathrm{pb}, 255 \mathrm{pb}, 295 \mathrm{pb}, 270 \mathrm{pb}$, $406 \mathrm{pb}$ y $371 \mathrm{pb}$, respectivamente.

Las cepas estudiadas fueron sembradas en agar tripticasa de soya por $24 \mathrm{~h}$ a $34^{\circ} \mathrm{C}$, con el fin de pesquisar las cepas heterogéneas. La extracción de ADN se llevó a cabo resuspendiendo una colonia en $100 \mu \mathrm{l}$ de agua estéril y calentando a ebullición durante $10 \mathrm{~min}$.

La mezcla de PCR se preparó con $5 \mu \mathrm{l}$ de la célula lisada, 0,2 $\mathrm{mM}$ de cada dNTPs, $0,5 \mu \mathrm{M}$ de cada partidor, $1 \mathrm{U}$ de Taq polimerasa, $10 \mathrm{x}$ PCR buffer y $1,5 \mathrm{mM}$ de cloruro de magnesio; volumen final $50 \mu \mathrm{l}$. La amplificación consistió en un ciclo inicial de $95^{\circ} \mathrm{C}$ por $5 \mathrm{~min} ; 30$ ciclos de $95^{\circ} \mathrm{C}$ por 30 $\mathrm{s}, 50^{\circ} \mathrm{C}$ por $30 \mathrm{~s}, 72^{\circ} \mathrm{C}$ por $30 \mathrm{~s}$; extensión final de $72^{\circ} \mathrm{C}$ por $10 \mathrm{~min}$. Los productos de amplificación fueron visualizados en geles de agarosa al $2 \%$, teñidos con bromuro de etidio.

Todos los ensayos se hicieron en triplicado, obteniéndose los mismos resultados.

Se utilizó como control negativo, la cepa de Staphylococcus aureus ATCC 29213 y como control positivo para las regiones hipervariables asociadas al gen mecA, una cepa analizada por otra institución (gentileza de María Teresa Ulloa, Universidad de Chile).

\section{Resultados}

Al implementar la técnica descrita por Huygens ${ }^{7}$, no se obtuvo una buena amplificación y resolución de los productos de amplificación esperados. 
Por esta razón, se optó modificarla a las condiciones de nuestro laboratorio, reemplazando el multiplex PCR por un ensayo de duplex PCR. Así, la amplificación se llevó a cabo incluyendo dos sets de partidores por reacción, por lo que el análisis de una cepa se realizó en cuatro reacciones individuales. Con esto se obtuvo una mejor amplificación de los productos esperados y, por ende, resultados confiables (Figura 1).

Se analizó un total de 55 cepas con fenotipo meticilino resistente. De ellas, 53 (96,3\%) presentaron al menos una de las ocho regiones hipervariables asociadas al gen mecA posibles de amplificar mediante la aplicación del ensayo duplex-PCR. Una de las cepas negativas para este ensayo fue clasificada erróneamente en un fenotipo de resistencia mediante MicroScan ${ }^{\circledR}$. La otra cepa negativa, presentó una resistencia mediada por hiperproducción de ß-lactamasa (datos no mostrados).

En las 41 cepas analizadas mediante CIM frente a oxacilina, se obtuvo $100 \%$ de concordancia con el duplex PCR. A su vez, MicroScan ${ }^{\circledR}$ clasificó tres $(5,4 \%)$ de 55 cepas, con un fenotipo diferente de acuerdo a los resultados obtenidos mediante el PCR (datos no mostrados).
Las 53 cepas que presentaron regiones hipervariables asociadas al gen mecA, se agruparon en 5 genotipos según las regiones amplificadas (Tabla 1). El genotipo más frecuentemente encontrado correspondió al genotipo 15 (37,7\%), seguido del genotipo $14(34,0 \%)$.

La distribución de los diferentes genotipos según servicio de aislamiento de la cepa, se detalla en la Tabla 2. Los servicios en que se encontró la mayor cantidad de cepas de SAMR correspondieron a Cirugía, Medicina y UCI con $26,4 \%, 22,6 \%$ y $20,7 \%$, respectivamente. Cabe destacar que en estos servicios predominan los genotipos 14 y 15, los cuales presentaron tres patrones de resistencia diferentes (Tabla 3).

De las 41 cepas analizadas mediante CIM, 87,8\% presentó resistencia simultánea a los 7 antimicrobianos estudiados (Figura 2). No se detectó cepas resistentes a vancomicina.

\section{DisCUSIÓN}

Un problema importante en clínica es dilucidar si la cepa de Staphylococcus aureus aislada de un

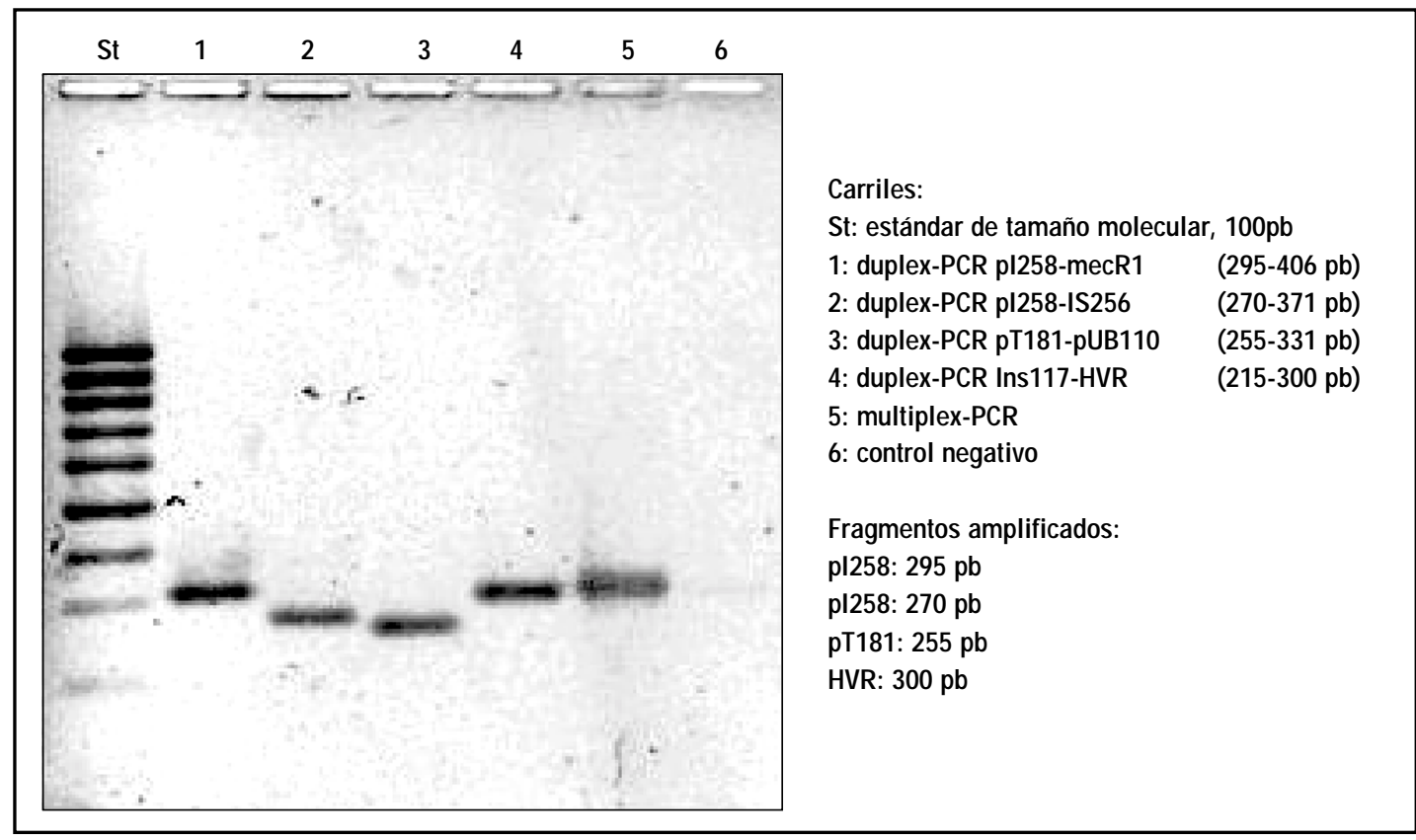

Figura 1. Modificación realizada a la técnica multiplex PCR de elementos variables asociados al mecA. El multiplex PCR descrito por Huygens ${ }^{7}$ (carril 5) fue dividido en cuatro duplex-PCR (carriles 1-4) para facilitar la interpretación de los resultados. 
Tabla 1. G enotipos identificados en 53 cepas de SAM R según región hipervariable amplificada

\begin{tabular}{|lcccccccr|}
\hline & \multicolumn{9}{c}{ Amplicones } \\
Genotipo & HVR & pUB110 & Ins117 & pT181 & pI258 & mecR1 & IS256 & \multicolumn{2}{c|}{ o cepas } \\
\hline $6^{*}$ & + & - & - & - & - & - & - & $6(11,3)$ \\
$14^{* * *}$ & + & - & - & + & + & - & - & $18(34,0)$ \\
$15^{* *}$ & + & - & - & - & + & - & - & $20(37,7)$ \\
$16^{* *}$ & + & - & - & - & + & - & + & $5(9,4)$ \\
$17^{* *}$ & + & - & - & + & - & - & - & $4(7,5)$ \\
\hline
\end{tabular}

*Único genotipo idéntico a Huygens ${ }^{7} .{ }^{* *}$ Genotipos nuevos, siguiendo la clasificación de Huygens ${ }^{7}$.

Tabla 2. N úmero de cepas por genotipo según servicio clínico

\begin{tabular}{|c|c|c|c|c|c|c|c|}
\hline \multirow[t]{2}{*}{ Servicio clínico } & \multicolumn{5}{|c|}{ Genotipos identificados } & \multirow{2}{*}{\multicolumn{2}{|c|}{$\begin{array}{c}\text { № de cepas } \\
(\%)\end{array}$}} \\
\hline & 6 & 14 & 15 & 16 & 17 & & \\
\hline Cirugía & 3 & 5 & 6 & & & 14 & $(26,4 \%)$ \\
\hline Medicina & 1 & 3 & 5 & 3 & & 12 & $(22,6 \%)$ \\
\hline UCI & & 5 & 3 & 2 & 1 & 11 & $(20,7 \%)$ \\
\hline Traumatología & & 2 & & & 1 & 3 & $(5,6 \%)$ \\
\hline Recién nacido & 1 & 1 & & & & 2 & $(3,7 \%)$ \\
\hline Oncología & & & 1 & & 1 & 2 & $(3,7 \%)$ \\
\hline Lactante & 1 & & 1 & & & 2 & $(3,7 \%)$ \\
\hline Ginecología & & 1 & & & 1 & 2 & $(3,7 \%)$ \\
\hline Urología & & & 1 & & & 1 & $(1,8 \%)$ \\
\hline Posoperatorio & & 1 & & & & 1 & $(1,8 \%)$ \\
\hline Pensionado & & & 1 & & & 1 & $(1,8 \%)$ \\
\hline Neonatología & & & 1 & & & 1 & $(1,8 \%)$ \\
\hline Neurología & & & 1 & & & 1 & $(1,8 \%)$ \\
\hline Total & 6 & 18 & 20 & 5 & 4 & 53 & \\
\hline Porcentaje & $11,3 \%$ & $33,9 \%$ & $37,7 \%$ & $9,4 \%$ & $7,5 \%$ & & \\
\hline
\end{tabular}

Tabla 3. Patrones de resistencia de 41 cepas estudiadas por CIM asociados a los genotipos

\begin{tabular}{|cccc|}
\hline Genotipo & Patrón de resistencia & cepas №/n & Porcentaje \\
\hline \multirow{2}{*}{14} & P-A-C-G-Ci-L-E* & $12 / 14$ & 86,0 \\
& P-A-C-Ci-L-E & $1 / 14$ & 7,1 \\
& P-A-C-G-Ci & $1 / 14$ & 7,1 \\
& & & 88,2 \\
15 & P-A-C-G-Ci-L-E & $15 / 17$ & 5,9 \\
& P-A-G-Ci-L-E & $1 / 17$ & 5,9 \\
& P-A-C-G-Ci & $1 / 17$ & 100 \\
16 & P-A-C-G-Ci-L-E & $4 / 4$ & 100 \\
6 & P-A-C-G-Ci-L-E & $4 / 4$ & 50 \\
& P-A-C-G-Ci-L-E & $1 / 2$ & 50 \\
\hline
\end{tabular}

*P: penicilina, A: ampicilina; C: cefradina; G: gentamicina; Ci: ciprofloxacino; L: lincomicina; E: eritromicina. 


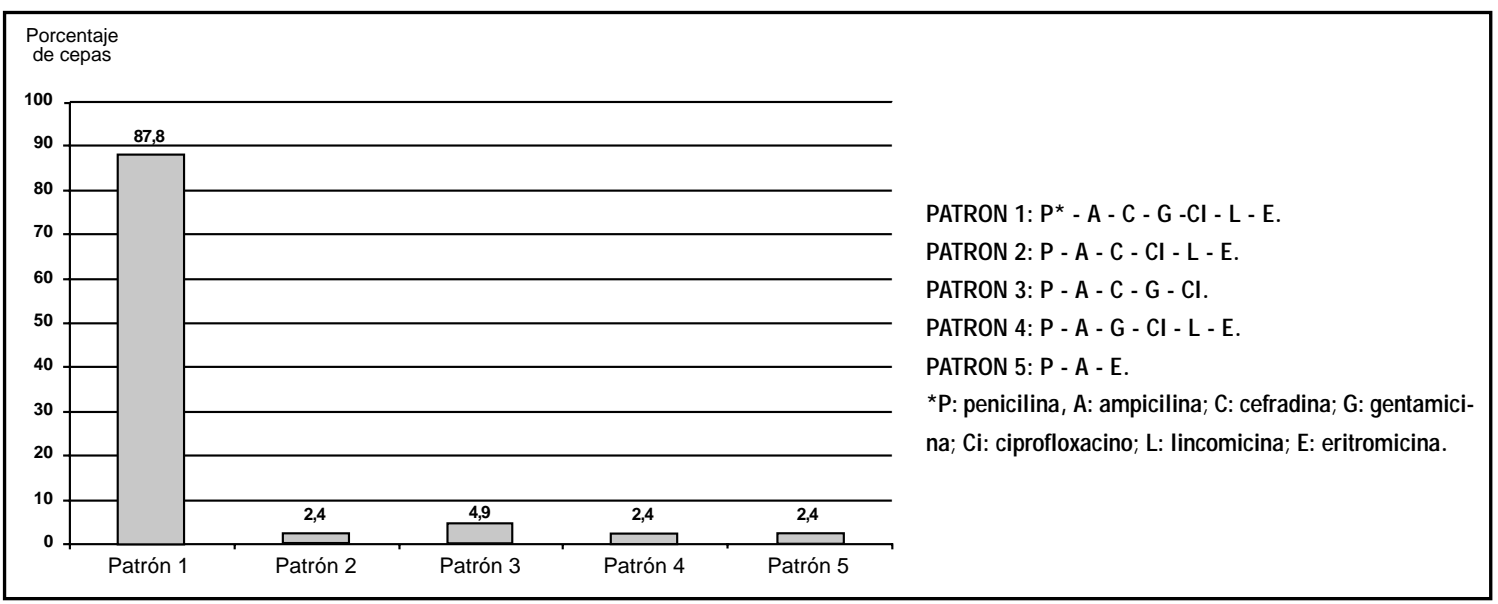

Figura 2. Porcentaje de patrones de resistencia de 41 cepas de SAMR

cuadro infeccioso es o no resistente a la oxacilina. Esto último debido a que constituye el antibiótico de elección utilizado para tratar las infecciones por Staphylococcus aureus. En la actualidad, se cuenta con diferentes técnicas para detectar SAMR, siendo las más utilizadas las fenotípicas. Estas presentan algunos inconvenientes, entre los que destaca, períodos de incubación variables dependiendo de la técnica y, además, el resultado puede verse afectado por la expresión heterogénea de resistencia a meticilina de la cepa ${ }^{5,9}$.

De las 55 cepas de Staphylococcus aureus estudiadas, 53 presentaron regiones hipervariables asociadas al gen mecA. A 41 de estas cepas se les determinó CIM frente a oxacilina, obteniéndose una correlación de 100\%. Este último método cuantitativo es recomendable aplicarlo cuando los demás métodos cualitativos de susceptibilidad antimicrobiana no son concluyentes ${ }^{10}$.

La determinación fenotípica de resistencia a meticilina mediante MicroScan ${ }^{\circledR}$ presentó errores $(5,4 \%)$, lo cual se debe a que los sistemas automatizados de microdilución poseen una menor sensibilidad, especificidad y eficacia diagnóstica, ya que no se consideran los múltiples factores que influyen en la expresión de la resistencia como son la temperatura de incubación, osmolaridad del medio, tiempo de incubación y densidad del inóculo ${ }^{6}$.

Sólo una de las cepas carentes de regiones hipervariables, fue clasificada como resistente a oxacilina mediante CIM y MicroScan ${ }^{\circledR}$. Posteriormente, se determinó que la resistencia no se debía a la producción de $\mathrm{PBP} 2 \mathrm{a}$, sino a una hiperproducción de R-lactamasas (BORSA).

Las cepas BORSA, a diferencia de las cepas SAMR, se caracterizan por ser susceptibles a antibióticos ß-lactámicos asociados a inhibidores de ß-lactamasas y por carecer del gen mecA $A^{6,11,12}$. La cepa en cuestión fue sensible a ampicilina-sulbactam, razón por la cual fue clasificada como una cepa BORSA. Es importante destacar que la cepa BORSA presentó una CIM frente a oxacilina de $8 \mu \mathrm{g} / \mathrm{ml}$, lo que la diferencia de las demás cepas SAMR que presentaron una CIM $\geq 16 \mu \mathrm{g} / \mathrm{ml}$.

Los procedimientos moleculares que permiten detectar la presencia del gen mecA son considerados métodos gold standard frente a la identificación de los SAMR.

En la actualidad se emplean diferentes metodologías moleculares para este fin, sin embargo, muchas de ellas son de elevado costo y muy laboriosas, por lo que no son de utilidad diagnóstica para la clínica $7,13,14$.

Por esta razón, en este trabajo se implementó un duplex PCR del gen mecA, basado en la técnica de multiplex PCR previamente descrita por Huygens ${ }^{7}$, la cual detecta la presencia o ausencia de regiones variables o elementos móviles asociados al gen mecA. Las 53 cepas que presentaron el 
gen mecA, se agruparon en 5 genotipos, de los cuales 4 fueron distintos a los descritos por Huygens ${ }^{7}$. Es decir, nuestras cepas amplificaron diferentes regiones a las previamente descritas y con el fin de seguir la clasificación, denominamos nuestros genotipos con los números 14, 15, 16 y 17. Sólo seis cepas concordaron con el genotipo 6 de la clasificación de Huygens ${ }^{7}$, aquélla que sólo amplificó la región HVR. Así, podemos inferir que en nuestro medio circulan cepas diferentes a las de Australia ${ }^{7}$.

Los servicios de procedencia en que se aisló el mayor número de SAMR fueron Cirugía, Medicina y UCI. Estos resultados son similares a los reportados por Otth y col en el año $1999^{15}$.

\section{REFERENCIAS}

1. Waldvogel F. Staphylococcus aureus. (Including Staphylococcal Toxic Shock). En: Mandell, Douglas \& Bennett's Principles and Practice of Infectious Diseases. Fifth ed 2000, Mandell GL, Bennett JE, Dolin R, eds., Churchill Livingstone, Philadelphia, pp 2070-92.

2. Jevons M. Celbenin-resistant Staphylococci. BMJ 1961; 1: 124-5.

3. Brown D, Edwars D, Hawkey P, Morrison D, Ridgway G, TOWNer K ET AL. Guidelines for the laboratory diagnosis and susceptibility testing of methicillin resistant Staphylococcus aureus (MRSA). J Antimicrob Chemother 2005; 56: 1000-18.

4. Lederman W, Mímica I. Sensibilidad in vitro del S aureus a meticilina y cloxacilina en los últimos ocho años (1961-1968). Rev Chil Pediat 1970; 41: 213.

5. Ulloa M, Porte L, Carmi K, Varela C, Fica A. Comparación de reacción de polimerasa en cadena, látex y antibiograma para detección de Staphylococcus aureus meticilino resistente. Rev Chil Infect 2001; 18: 255-60.

6. GIL M. Staphylococcus aureus: Microbiología y aspectos moleculares de la resistencia a meticilina. Rev Chil Infect 2000; 17: 145-52.

7. Huygens F, Nimmo G, Schooneveldt J, Munckhof W, GIFFARD P. Genotyping of Methicillin-Resistant Staphylococcus aureus by Assaying for the Presence of Variable Elements Associated with mecA. J Clin Microbiol 2002; 40: 3093-107.
El alto porcentaje de resistencia simultánea frente a los antibióticos analizados da cuenta de la gran probabilidad de que cepas meticilino resistentes presenten multirresistencia, lo cual es de gran importancia al elegir el tratamiento antimicrobiano. De allí la necesidad de implementar técnicas moleculares de diagnóstico, las cuales entregan resultados rápidos y confiables.

Considerando las modificaciones realizadas por nuestro laboratorio a la técnica descrita por Huygens $^{7}$ sugerimos que la implementación de ella en los laboratorios asistenciales sería de gran utilidad, tanto para determinar la presencia de regiones hipervariables asociadas al gen mecA, como para eventuales seguimientos epidemiológicos.

8. National Committee for Clinical Laboratory StanDARS. Methods for Dilution Antimicrobial Susceptibility Test for Bacteria that Grow Aerobically: Approved Standart M7-A6. NCCLS; Wayne, PA, USA. 2003.

9. Louie L, Matsumura S, Chor E, Simor A. Evaluation of Three Rapid Methods for Detection of Methicillin Resistance in Staphylococcus aureus. J Clin Microbiol 2000; 38: 2170-3.

10. Camarena J, Sánchez R. Infección por Staphylococcus aureus resistente a meticilina. Control Calidad SEIMC. Disponible en: http://www. seimc.org/control/revi_Bacte/sarm.htm. (Consultado el 7 de agosto de 2006)

11. Martínez J. Antibióticos y Quimioterápicos Antimicrobianos. $2^{\underline{a}}$ ed. Universidad de Concepción, 1990.

12. Mcdougal L, Thornsberry C. The role of $§-$ lactamase in staphylococcal resistance to penicillinase-resistant penicillin and cephalosporins. J Clin Microbiol 1986; 23: 832-9.

13. Trindade P, McCulloch J, Oliveira G, Mamizuka E. Molecular Techniques for MRSA Typing: Current Issues and Perspectivas. BJID 2003; 7: 32-3.

14. Shopsin B, Kreiswirth B. Molecular Epidemiology of Methicillin-resistant Staphylococcus aureus. Emerging Infectious Diseases 2001; 7: 323-6.

15. Отth L, Milson M, Zaror A, Arce M, Lizama V. Aislamiento de Staphylococcus aureus meticilino resistente en pacientes atendidos en el Hospital Clínico Regional de Valdivia. Cuad Cir 1999; 13 : 55-8. 